\title{
Connection Stability Analysis of Segmental Geosynthetic Reinforced Soil (GRS) Walls
}

\author{
Jonathan T. H. Wu • Jean-Baptiste Payeur
}

Accepted: 14 August 2014 / Published online: 22 August 2014

C) Springer New York 2014

\begin{abstract}
There have been ongoing arguments whether heavy blocks and/or facing connection enhancement elements, such as pins, lips, or keys, are needed for facing stability of segmental reinforced soil walls with geosynthetic reinforcement. This study was undertaken to examine facing connection forces for vertical or near vertical segmental reinforced soil walls with purely friction connections. In the study, the lateral earth pressure was assumed to be the Rankine active earth pressure - an assumption that has been employed by most current design methods of reinforced soil walls with extensible reinforcement. Based on force equilibrium, the driving forces and resisting forces at facing connections are derived for situations where reinforcement is at every course of facing blocks and at every three courses of facing blocks. For the latter, both the connection forces at geosynthetic-block interface and at block-block interface are considered. Based on these connection force equations, generalized equations of driving and resisting forces for any number courses of blocks between adjacent reinforcement layers are developed. Using the generalized connection force equations, comparisons of driving and resisting forces for some common parameter values and under typical conditions of reinforced soil walls were performed. The significance of reinforcement spacing, as well as the need, or lack thereof, for heavy facing blocks and/or additional connection measures on facing stability is discussed. The benefit of small reinforcement spacing is demonstrated. A common perception that a higher wall is more susceptible to connection failure is true only for segmental walls with larger reinforcement spacing.
\end{abstract}

\footnotetext{
J. T. H. Wu $(\bowtie)$

Reinforced Soil Research Center, University of Colorado Denver, Denver, CO 80217, USA

e-mail: jonathan.wu@ucdenver.edu

J. T. H. Wu

Civil Engineering Department, University of Colorado Denver, Denver, CO 80217, USA

J.-B. Payeur

Laboratoire Navier, Université Paris-Est, Marne-la-Vallée, France

e-mail: payeurj@cermes.enpc.fr
} 
Keywords Connection forces $\cdot$ Geosynthetics $\cdot$ Reinforced soil $\cdot$ Segmental walls $\cdot$ Reinforcement spacing $\cdot$ Equation

\section{Introduction}

Among various types of reinforced soil walls, segmental reinforced soil wall with geosynthetics as reinforcement is becoming very popular in North America. The popularity arises because the facing units of segmental reinforced soil walls are readily available, and segmental walls are much easier and more rapid to construct, more economical, and more adaptable to various topographical and geometrical conditions than other types of reinforced soil walls.

Segmental reinforced soil walls comprise two major components: a geosynthetic reinforced soil mass and a wall face that is composed of stacked modular facing units. Different materials of different forms have been used for the modular facing units, with concrete blocks being the most common. The geosynthetic reinforced soil mass, on the other hand, is always compacted fill with horizontal layers of geosynthetic inclusion.

The behavior of geosynthetic reinforced soil mass has been the subject of many studies. The significant benefit of small reinforcement spacing (on the order of 0.1 to $0.3 \mathrm{~m}$ ) for increased stiffness and strength of a reinforced soil mass has been investigated analytically by $\mathrm{Wu}$ and Pham [17] and verified by many full-scale experiments (e.g., $[3,8,10,12,16])$ as well as hundreds of walls in actual construction $[4,5]$. The ultimate load-carrying capacity of a reinforced soil mass has been found to be well over $1,000 \mathrm{kPa}$ with medium strength geosynthetic reinforcement at $0.2-\mathrm{m}$ spacing and a well-compacted granular backfill. Those studies have suggested that a reinforced soil mass with closely spaced reinforcement can be internally stabilized, i.e., it can be stable under substantial loads without the aid of any facing. The segmental facing of a reinforced soil wall with closely spaced reinforcement, therefore, only needs to serve as a construction aid, as protection for sloughing of vertical face, and as the façade for the reinforced soil mass. Segmental facing, however, does enhance stability and reduces deformation of a geosynthetic reinforced soil wall (e.g., [11]). The role of facing rigidity on performance of reinforced soil walls has been investigated in a series of studies conducted at the University of Tokyo [13]. Figure 1 shows the schematic diagram of a segmental reinforced soil wall with closely spaced geosynthetic reinforcement.

Recently, the Federal Highway Administration (FHWA) developed a geosynthetic reinforced soil bridge abutment system, called "Geosynthetic Reinforced SoilIntegrated Bridge System (GRS-IBS)," with geosynthetic reinforcement at close spacing $[2,3]$. Following the definition of the FHWA, geosynthetic reinforced soil (GRS) is referred to a soil mass that is reinforced by horizontal layers of geosynthetic reinforcement at vertical spacing not more than $0.3 \mathrm{~m}$.

It is noteworthy that GRS walls bear strong resemblance to Mechanically Stabilized Earth (MSE) walls. The two systems, however, are different in the fundamental design concept. A GRS wall incorporates geosynthetic reinforcement in a soil mass to improve the engineering properties of the soil mass, hence the term reinforced in GRS, while an MSE wall uses reinforcement as quasi-tiebacks, i.e., to help stabilizing a potential failure wedge (assumed to be formed between a critical slip plane and wall face) and 


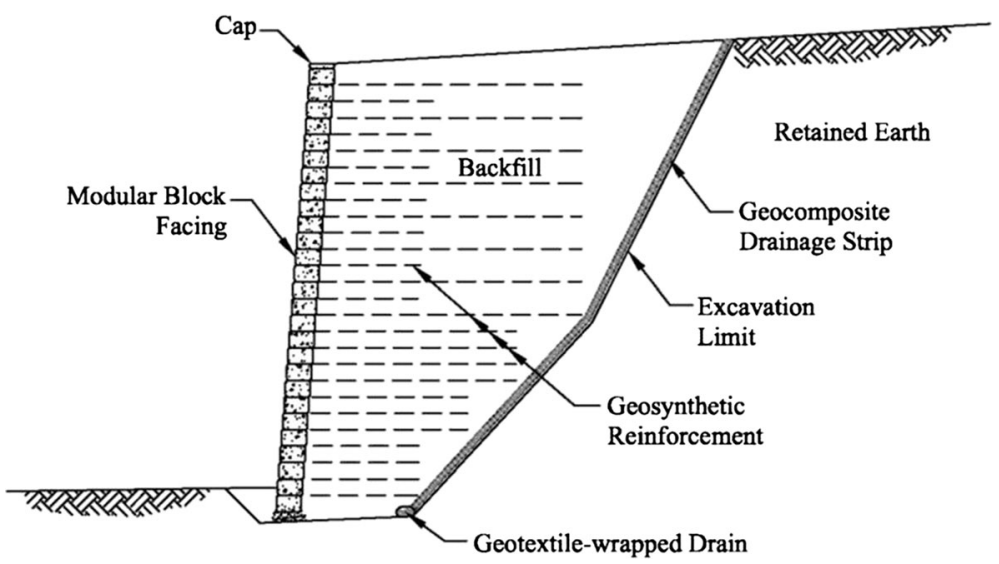

Fig. 1 Schematic diagram of a typical segmental reinforced soil wall with closely spaced geosynthetic reinforcement

prevent it from reaching a failure condition, hence the term stabilized in MSE. Since closely spaced reinforcement tends to produce elevated improvement of the stiffness and strength of the soil geosynthetic composite, GRS walls have typically been constructed with vertical spacing of $0.2 \mathrm{~m}$. On the other hand, spacing has little effect on a tieback system, and MSE walls have typically been constructed with much larger vertical spacing of 0.3 to $1.0 \mathrm{~m}$ to save construction time.

Traditional earth retaining walls, such as gravity and cantilever concrete walls, can be considered externally stabilized, which rely on external structural components to retain the soil behind it and to resist the earth pressure exerted on the walls. Many designers of reinforced soil walls are not entirely comfortable with the discrete nature of segmental facing of reinforced soil walls. As a result, most designers have opted for a hybrid externally and internally stabilized wall, by using heavy facing blocks (weights on the order of 150 to $250 \mathrm{~N}$ per block) in conjunction with connection enhancement elements, such as pins, lips, or keys between vertically adjacent facing blocks. They consider these measures necessary for added stability of segmental facing.

The idea that a GRS mass can be internally stabilized, however, has not gone unnoticed. Recognizing that there is a major difference between lateral stress in a reinforced soil mass and lateral pressure acting on wall face, $\mathrm{Wu}$ et al. [14, 15] proposed a bin pressure postulate. In the bin pressure postulate, the lateral earth pressure that develops between any two successive layers of reinforcement is primarily a function of reinforcement spacing and independent of wall height. The resulting lateral earth thrust is very small for GRS walls for closely spaced reinforcement. Hundreds of small-spacing segmental GRS walls have been designed with the bin pressure postulate and constructed using dry-stacked cinder blocks (i.e., concrete masonry units, CMU) without any connection enhancement elements [14]. These walls have performed satisfactorily. A glaring example is a GRS wall in Grand County, Colorado (see Fig. 2), with the tallest point that stands $16.7 \mathrm{~m}$. The face of the wall comprised dry-stacked lightweight concrete blocks without any connection enhancement elements. Geosynthetic reinforcement was at every course of block, i.e., at 0.2-m spacing. The wall has performed satisfactorily without experiencing any sign of distress since construction in 1997. Iwamoto et al. [10] recently reported a series of full-scale 


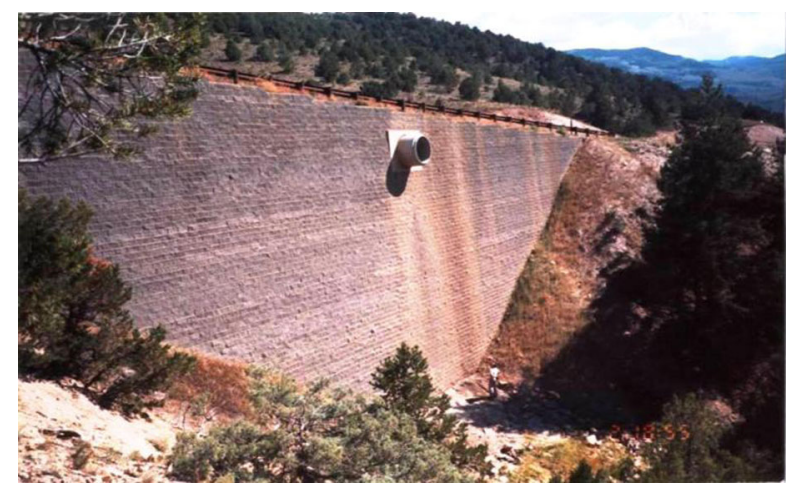

Fig. 2 A 16.7-m-high GRS wall with lightweight frictionally connected segmental facing

load tests of GRS piers conducted by the FHWA. The piers were constructed with segmental block facing. The interior faces of the piers were instrumented to monitor lateral earth pressure on segmental facing. They concluded that the measured pressure agreed well with the bin pressure postulate. With the bin pressure postulate, facing stability of segmental GRS walls is assured as long as the reinforcement spacing is kept small.

It is of significant practical interest to investigate connection stability of segmental facing by examining the facing connection forces for different values of reinforcement spacing and for different block weights. To be on the conservative side, the lateral earth pressure in this study is assumed to be the Rankine active earth pressure, which has been recommended for design of reinforced soil walls with extensible reinforcement in nearly every prevailing design methods, including the AASHTO method [1] and the FHWA method [6].

In this paper, the driving forces and resisting forces at segmental facing connections are derived, based on equilibrium of forces, for situations where reinforcement is at every course of facing blocks and every three courses of facing blocks. For the latter, both connection forces at geosynthetic-block interface and block-block interface are examined. Based on the equations for the connection forces, generalized equations for any number courses of blocks between adjacent reinforcement layers are developed. Using the generalized connection force equations, comparisons of driving and resisting forces for some common parameter values under typical conditions of a reinforced soil wall are performed. The significance of reinforcement spacing, as well as the need, or lack thereof, for heavy facing blocks and/or additional connection measures is discussed.

\section{Connection Forces}

In this section, the limiting driving force and resisting force at facing connections of a segmental reinforced soil wall are derived based on simple equilibrium of forces. These forces are referred to as connection forces. Connection failure is said to occur when driving force $\left(D_{i}\right)$ is greater than resisting force $\left(R_{i}\right)$ at any connection. The connection forces with reinforcement at every course of facing blocks were derived first, then the 
forces at every three courses of facing blocks. Based on the expressions for connection forces, generalized equations for connection forces for any number courses of blocks between adjacent reinforcement sheets are presented. This section begins with a description of the assumptions made in the derivation and follows by derivations of driving and resisting forces for the various conditions.

\section{Assumptions}

A number of assumptions were made for the derivation of the connection forces developed between adjacent facing blocks of segmental reinforced soil walls. The assumptions include the following:

- The wall is essentially vertical and can be approximated as in a plane strain condition.

- The facing blocks are dry-stacked (i.e., without mortar or other adhesives) and with friction connection (i.e., essentially flat top and bottom surfaces without lips or keys and without any mechanical connection pins).

- Geosynthetic reinforcement is extended to the front edge of facing blocks.

- A uniform surcharge, when present, is applied over the horizontal wall crest.

- Each facing block is rigid. The limiting connection force between contact surfaces follows Coulomb dry friction theory.

- The lateral earth pressure exerted by the soil on the back of wall face follows the active Rankine earth pressure theory.

- The downdrag forces by the reinforcement (due to settlement of reinforced fill) on the blocks below are ignored for conservatism (by ignoring the downdrag forces, the normal forces, hence the frictional resistance, on horizontal contact surfaces between facing blocks become smaller, therefore more conservative from the standpoint of facing stability).

Connection Forces with Geosynthetic Reinforcement at Every Course of Facing Blocks

To determine the connection forces for geosynthetic reinforcement at every course of facing blocks, let us consider the free body diagram of two blocks taken from a segmental reinforced soil wall face at depth $z_{\mathrm{i}}$, with forces acting on the free body diagram shown in Fig. 3. With a geosynthetic reinforcement sheet at every course of facing block, reinforcement spacing is equal to block height $\left(S_{v}=h\right)$. Note that the free body diagram, as well as all other free body diagrams shown in the paper, assumes that the blocks are of unit length (in the direction perpendicular to the drawing); thus, all forces are in the units of force per unit length.

Equilibrium of forces in vertical and horizontal directions leads to the following two equations:

$$
\begin{aligned}
& \text { Vertical Forces: } \boldsymbol{W}_{\boldsymbol{i}}+\boldsymbol{N}_{\boldsymbol{i}-1}-\boldsymbol{N}_{\boldsymbol{i}+1}+\boldsymbol{F}_{\boldsymbol{b} \boldsymbol{i}}=0 \\
& \text { Horizontal Forces : } \boldsymbol{T}_{\boldsymbol{i}}+\boldsymbol{F}_{\boldsymbol{i}+1}-\boldsymbol{F}_{\boldsymbol{i}-1}-\boldsymbol{P}_{\boldsymbol{i}}=0
\end{aligned}
$$




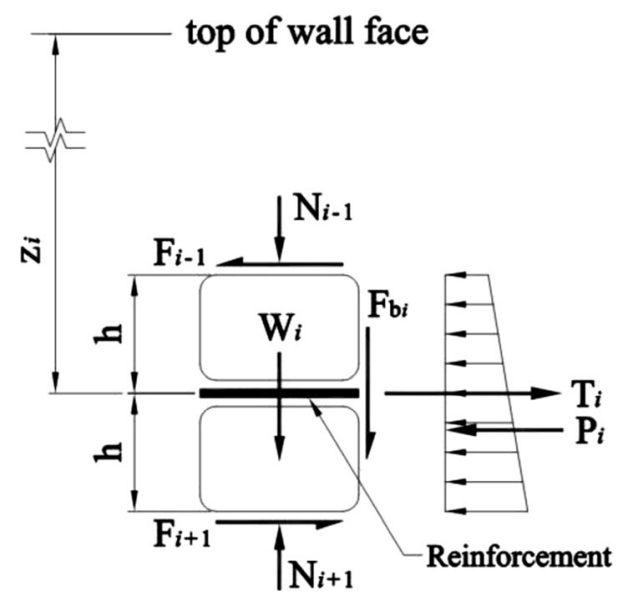

Fig. 3 Free body diagram of a reinforcement sheet sandwiched between two facing blocks

The terms in the above equations are shown in Fig. 3, where $W$ represents selfweight of blocks, $N$ represents normal force, $F$ represents shear force, $T$ represents tensile force in reinforcement at connection, and $P$ represents the resultant thrust from the soil acting on the back of the facing blocks.

Assuming the lateral earth pressure on the facing follows the Rankine active pressure theory, i.e.,

$$
\boldsymbol{P}_{\boldsymbol{i}}=\boldsymbol{K}_{\boldsymbol{a}}\left(\gamma_{s} \boldsymbol{Z}_{\boldsymbol{i}}+\boldsymbol{q}\right)(2 \boldsymbol{h})
$$

where $P_{i}=$ resultant soil thrust behind the blocks in consideration, $K_{a}=\left(1-\sin \varphi_{\mathrm{ps}}\right) /(1+$ $\sin \varphi_{\mathrm{ps}}$ ), and $\sin \varphi_{\mathrm{ps}}$ is plane strain angle of friction, $\gamma_{s}=$ unit weight of fill behind block facing, $z_{i}=$ depth at midheight of the blocks under consideration, measured from the top of facing (as shown in Fig. 3), $q=$ uniform surcharge over reinforced soil mass, and $h=$ height of each facing block.

If the blocks are bonded through friction only, based on Coulomb's friction theory,

$$
\begin{gathered}
F_{i-1}=N_{i-1} \tan \delta_{g b} \\
F_{i+1}=N_{i+1} \tan \delta_{g b}
\end{gathered}
$$

where $\delta_{g b}$ is the angle of friction between geosynthetic reinforcement and top/bottom surface of facing block.

Substituting Eqs. (4) and (5) into Eq. (2), then combining it with Eq. (1), we obtain $T_{i}$, the tensile reinforcement force at depth $z_{i}$, as the following:

$$
\boldsymbol{T}_{i}=-\tan \delta_{g b}\left(\boldsymbol{W}_{i}+\boldsymbol{F}_{b i}\right)+\boldsymbol{P}_{\boldsymbol{i}}
$$

The weight of the two blocks in the free body diagram (Fig. 3), $W_{i}$, is

$$
\boldsymbol{W}_{\boldsymbol{i}}=2 \boldsymbol{h} \boldsymbol{B} \gamma_{\boldsymbol{b}}
$$


in which $h=$ height of each facing block, $\gamma_{b}=$ bulk unit weight of facing block, and $B=$ depth (in the direction perpendicular to wall face) of facing block.

The frictional force along the contact surface between the backface of the two facing blocks in consideration and soil, $F_{b i}$, is

$$
\boldsymbol{F}_{\boldsymbol{b i}}=\overline{\boldsymbol{p}}(2 \boldsymbol{h}) \tan \delta_{s b}
$$

In Eq. (8), $\overline{\boldsymbol{p}}$ is the net earth pressure exerted by soil on the backface of the two blocks in consideration, and $\delta_{s b}$ is the angle of friction between backface of blocks and soil behind the blocks.

\section{Driving Force at Connection, $D_{i}$}

The driving force at connection, $D_{i}$, is equal to the tensile force in reinforcement, $T_{i}$. To compute the tensile force in the reinforcement, $T_{i}$, we should consider the horizontal forces acting on the backface of the blocks. Equilibrium of forces gives

$$
\overline{\boldsymbol{p}}(2 \boldsymbol{h})=\boldsymbol{P}_{\boldsymbol{i}}-\boldsymbol{T}_{\boldsymbol{i}}
$$

Substituting Eq. (6) into Eq. (9), the net earth pressure, $\overline{\boldsymbol{p}}$, becomes

$$
\bar{p}=\frac{\tan \delta_{g b}}{2 h}\left(W_{i}+F_{b i}\right)
$$

Note that the net earth pressure, $\overline{\boldsymbol{p}}$, is a function of block height and is independent of depth. Substituting Eqs. (7) and (8) into Eq. (10) yields

$$
\bar{p}=\frac{B \gamma_{b}\left(\tan \delta_{g b}\right)}{1-\left(\tan \delta_{g b}\right)\left(\tan \delta_{s b}\right)}
$$

Therefore,

$$
\boldsymbol{D}_{i\left(S_{v}=h\right)}=\boldsymbol{T}_{i\left(S_{v}=h\right)}=2 \boldsymbol{h} \boldsymbol{K}_{a}\left(\gamma_{s} \boldsymbol{Z}_{i}+\boldsymbol{q}\right)-2 \boldsymbol{h}\left[\frac{\boldsymbol{B} \gamma_{\boldsymbol{b}}\left(\tan \delta_{g b}\right)}{1-\left(\tan \delta_{g b}\right)\left(\tan \delta_{s b}\right)}\right]
$$

where $D_{i}$ is the driving force at depth $z_{i}$ and $T_{i}$ is the force in the reinforcement at depth $z_{i}$. The term $\mathrm{K}_{\mathrm{a}}$ in the equation can be replaced by a different lateral pressure coefficient if a state other than the Ranike active pressure is assumed. Note that since geosynthetic can only resist tensile force, $D_{i} \geq 0$. If $D_{i}<0, D_{i}$ should be set as being 0 . Note also that the net pressure, as expressed in Eq. (11), is independent of depth.

\section{Resisting Force at Connection, $R_{i}$}

As geosynthetic reinforcement is sandwiched between facing blocks, we need to determine the frictional resistance at the geosynthetic reinforcement-block interface, $R_{\mathrm{i}}$. If the frictional resistance $\left(R_{i}\right)$ is less than reinforcement tensile force, $T_{i}$ (which is equal to driving force), connection failure will occur along that particular contact surface. 
From the free body diagram shown in Fig. 3, we have

$$
\boldsymbol{R}_{i}=\left(\boldsymbol{N}_{i+1}-\boldsymbol{N}_{i-1}\right) \tan \delta_{g b}
$$

From Eq. (1),

$$
\boldsymbol{N}_{i+1}=\boldsymbol{W}_{\boldsymbol{i}}+\boldsymbol{N}_{\boldsymbol{i}-1}+\boldsymbol{F}_{\boldsymbol{b i}}
$$

Substituting Eq. (13) into Eq. (14), we have

$$
\boldsymbol{R}_{\boldsymbol{i}}=\left(\boldsymbol{W}_{\boldsymbol{i}}+\boldsymbol{F}_{\boldsymbol{b i}}\right) \boldsymbol{t a n} \delta_{g b}
$$

Substituting Eqs. (7), (8), and (10) into Eq. (15), we have

$$
\boldsymbol{R}_{i\left(S_{v}=h\right)}=2 \boldsymbol{B} \gamma_{b} \boldsymbol{Z}_{\boldsymbol{i}}\left(\boldsymbol{t a n} \delta_{g b}\right)+2 \boldsymbol{B} \gamma_{b} \boldsymbol{h}\left[\frac{\left(\tan \delta_{s b}\right)\left(\tan ^{2} \boldsymbol{\delta}_{g b}\right)}{1-\left(\tan \delta_{g b}\right)\left(\tan \delta_{s b}\right)}\right]
$$

Connection Forces with Geosynthetic Reinforcement at Every Three Course of Facing Blocks

Figure 4 shows the free body diagrams of six facing blocks taken from the facing of a segmental reinforced soil wall with a reinforcement sheet at every three courses of facing blocks. For this case, we need to examine the conditions under which failure occurs at the connection along (a) geosynthetic-block interface and (b) block-block interface.

\section{Connection Failure at Geosynthetic-Block Interface}

Assuming that there is no relative displacement among the three blocks between adjacent sheets of reinforcement (this assumption will be checked later in b), the free

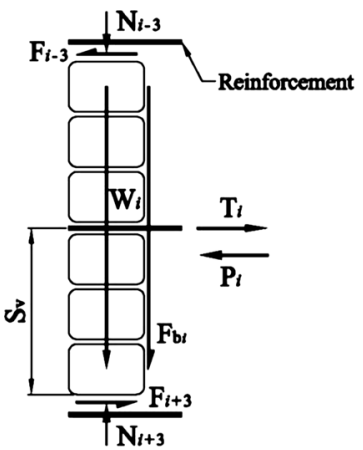

(a)

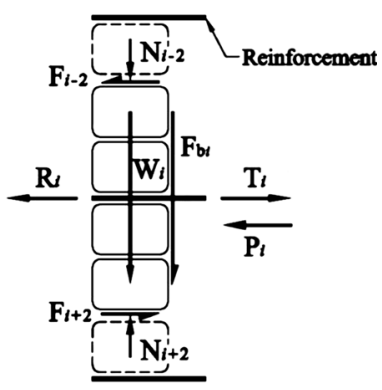

(b)

Fig. 4 Free body diagrams of block facing with three courses of blocks between reinforcement sheets a without relative movement among the blocks and $\mathbf{b}$ with relative movement between blocks 
body diagram shown in Fig. 4a can be regarded as being equivalent to the previous case where reinforcement is at every course of blocks $\left(S_{v}=h\right)$, except that the block height is now equal to $3 h$.

The driving force, $D_{i}$, is equal to tensile reinforcement force at connection, $T_{i}$, hence

$$
\begin{aligned}
\boldsymbol{D}_{\boldsymbol{i}\left(\boldsymbol{S}_{v}=3 \boldsymbol{h}\right)} & =\boldsymbol{T}_{\boldsymbol{i}\left(\boldsymbol{S}_{v}=3 \boldsymbol{h}\right)}=6 \boldsymbol{K}_{\boldsymbol{a}} \boldsymbol{h}\left(\gamma_{s} \mathbf{z}_{\boldsymbol{i}}+\boldsymbol{q}\right)-6 \boldsymbol{h}\left[\frac{\boldsymbol{B} \gamma_{\boldsymbol{b}}\left(\tan \delta_{g b}\right)}{1-\left(\tan \delta_{g b}\right)\left(\tan \delta_{s b}\right)}\right] \\
& =3 \boldsymbol{T}_{\boldsymbol{i}\left(S_{v}=h\right)}
\end{aligned}
$$

The frictional resistance, $R_{i}$, becomes

$$
\boldsymbol{R}_{i\left(S_{v}=3 h\right)}=2 \boldsymbol{B} \gamma_{b} \boldsymbol{Z}_{i}\left(\tan \delta_{g b}\right)+6 h \boldsymbol{B} \gamma_{b}\left[\frac{\left(\tan _{s b}\right)\left(\tan ^{2} \delta_{g b}\right)}{1-\left(\tan \delta_{g b}\right)\left(\tan \delta_{s b}\right)}\right]
$$

\section{Connection Failure at Block-Block Interface}

We also need to examine the conditions under which there may be relative movement (sliding) among the blocks between adjacent reinforcement sheets. Let us consider the free body diagram shown in Fig. 4b, which includes four courses of facing blocks, two above a reinforcement sheet and two below.

Equilibrium of forces in vertical and horizontal directions leads to

$$
\boldsymbol{T}_{\boldsymbol{i}\left(\boldsymbol{S}_{v}=2 \boldsymbol{h}\right)}=-\left(\boldsymbol{W}_{\boldsymbol{i}}+\boldsymbol{F}_{\boldsymbol{b i}}\right) \tan \delta_{b \boldsymbol{b}}+\boldsymbol{P}_{\boldsymbol{i}}
$$

where $\delta_{\mathrm{bb}}$ is the angle of friction between top and bottom surfaces of two contacting blocks.

Considering no relative movement between two blocks, i.e., an equivalent block height of $2 h$ between reinforcement sheets, we have

$$
\boldsymbol{D}_{i\left(S_{v}=2 h\right)}=\boldsymbol{T}_{\boldsymbol{i}\left(\boldsymbol{S}_{v}=2 \boldsymbol{h}\right)}=4 \boldsymbol{K}_{a} \boldsymbol{h}\left(\gamma_{s} \mathbf{z}_{i}+\boldsymbol{q}\right)-4 \boldsymbol{h}\left[\frac{\boldsymbol{B} \gamma_{\boldsymbol{b}}\left(\tan \delta_{b b}\right)}{1-\left(\tan \delta_{b b}\right)\left(\tan \delta_{s b}\right)}\right]
$$

The corresponding frictional resistance, $R_{i}$, becomes

$$
\boldsymbol{R}_{\boldsymbol{i}\left(\boldsymbol{S}_{v}=2 \boldsymbol{h}\right)}=2 \boldsymbol{B} \gamma_{b} \boldsymbol{z}_{\boldsymbol{i}}\left(\boldsymbol{t a n} \boldsymbol{\delta}_{\boldsymbol{b} b}\right)+4 \boldsymbol{h B} \gamma_{\boldsymbol{b}}\left[\frac{\left(\tan \delta_{s b}\right)\left(\tan ^{2} \boldsymbol{\delta}_{b b}\right)}{1-\left(\tan \delta_{b b}\right)\left(\tan \delta_{s b}\right)}\right]
$$

Note that if we consider force equilibrium involving only one course of facing blocks above and below a reinforcement sheet, we will have

$$
\begin{aligned}
\boldsymbol{D}_{\boldsymbol{i}\left(\boldsymbol{S}_{v}=\boldsymbol{h}\right)} & =\boldsymbol{T}_{\boldsymbol{i}\left(\boldsymbol{S}_{v}=\boldsymbol{h}\right)}=2 \boldsymbol{K}_{\boldsymbol{a}} \boldsymbol{h}\left(\gamma_{s} \mathbf{z}_{i}+\boldsymbol{q}\right)-2 \boldsymbol{h}\left[\frac{\boldsymbol{B} \gamma_{\boldsymbol{b}}\left(\boldsymbol{t a n} \delta_{b b}\right)}{1-\left(\tan \delta_{b b}\right)\left(\tan \delta_{s b}\right)}\right] \\
& =\frac{\boldsymbol{T}_{\boldsymbol{i}\left(\boldsymbol{S}_{v}=2 \boldsymbol{h}\right)}}{2}
\end{aligned}
$$




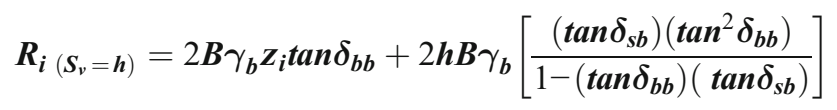

The frictional resistance, $R_{\mathrm{i}}(\mathrm{Sv}=\mathrm{h})$, determined by Eq. (23), is only slightly smaller

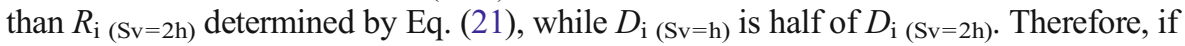
the block-block interface failure for two courses of blocks above and below a reinforcement sheet is satisfied, the connection failure condition for one course of blocks above and below a reinforcement sheet will be satisfied for all probable values of the parameters involved. In other words, the condition for block-block interface failure is always more critical for higher number of courses of blocks above and below a reinforcement sheet. As a result, block-block interface failure needs only be evaluated for the condition of the highest number of courses of facing blocks above and below a reinforcement sheet.

\section{Generalized Equations for Connection Forces}

Based on the equations derived in this section, generalized equations for the driving force $(D i)$ and resisting force $(R i)$ can be readily obtained. The equations for $D_{i}$ and $R_{i}$ for " $n$ " courses of facing blocks between adjacent reinforcement sheets, i.e., for $S_{v}=n * h$ ( $S_{\mathrm{v}}=$ reinforcement spacing and $h=$ block height $)$, can be expressed as follows. When reinforcement is placed at every course of facing block, only connection failure at soil-reinforcement interface needs to be examined. However, if there is more than one course of facing blocks between adjacent reinforcement sheets, both connection failure at geosynthetic-block interface and connection failure at block-block interface need to be examined. Connection failure will occur at any depths where $D_{i}>R_{i}$.

Check connection failure at geosynthetic-block interface:

$$
\begin{gathered}
\boldsymbol{D}_{\boldsymbol{i}}=2 \boldsymbol{n h} \boldsymbol{K}_{\boldsymbol{a}}\left(\gamma_{s} \mathbf{z}_{\boldsymbol{i}}+\boldsymbol{q}\right)-2 \boldsymbol{n h}\left[\frac{\boldsymbol{B} \gamma_{\boldsymbol{b}}\left(\tan \delta_{g b}\right)}{1-\left(\tan \delta_{g b}\right)\left(\tan \delta_{s b}\right)}\right] \\
\boldsymbol{R}_{\boldsymbol{i}}=2 \boldsymbol{B} \gamma_{\boldsymbol{b}} \boldsymbol{Z}_{\boldsymbol{i}}\left(\boldsymbol{t a n} \delta_{g b}\right)+2 \boldsymbol{n} \boldsymbol{h} \boldsymbol{B} \gamma_{\boldsymbol{b}}\left[\frac{\left(\tan \delta_{s b}\right)\left(\tan ^{2} \delta_{g b}\right)}{1-\left(\tan \delta_{g b}\right)\left(\tan \delta_{s b}\right)}\right]
\end{gathered}
$$

Check connection failure at block-block interface (applicable only to $n \geq 2$ ):

$$
\begin{aligned}
& \boldsymbol{D}_{\boldsymbol{i}}=2(\boldsymbol{n}-1) \boldsymbol{h} \boldsymbol{K}_{\boldsymbol{a}}\left(\gamma_{s} \mathbf{z}_{\boldsymbol{i}}+\boldsymbol{q}\right)-2(\boldsymbol{n}-1) \boldsymbol{h}\left[\frac{\boldsymbol{B} \gamma_{\boldsymbol{b}}\left(\boldsymbol{t a n} \boldsymbol{\delta}_{\boldsymbol{b} b}\right)}{1-\left(\boldsymbol{t a n} \boldsymbol{\delta}_{\boldsymbol{b} b}\right)\left(\boldsymbol{t a n} \boldsymbol{\delta}_{s b}\right)}\right]
\end{aligned}
$$

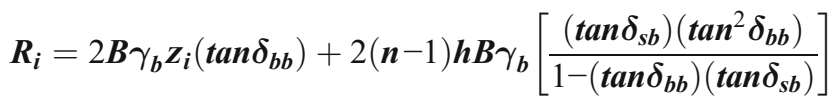

Since geosynthetic reinforcement can only resist tensile force, when a driving force $D_{i}$ in Eqs. (24) or (26) is calculated as a negative value (compressive), it should be set 
as 0 . It is noteworthy that the lead and second authors have derived the above equations independently to provide a cross-check on the generalized equations.

\section{Parametric Study and Discussions}

With the generalized equations of connection forces, i.e., Eqs. (24) to (27), one can readily evaluate the driving forces and resisting forces for segmental facing of any given geometric conditions and material properties. A preliminary parametric study is presented here to illustrate the effects of some parameters. It was not intended for the parametric study to be an exhaustive investigation of how each of the parameters would affect the connection forces. For the parametric study, a baseline case was first defined and followed by the preliminary parametric study based on the baseline case.

For the baseline case, the following values representing those of a typical reinforced soil wall were selected: wall height, $H=6 \mathrm{~m}$; height of each facing block, $h=0.2 \mathrm{~m}$; number of facing blocks between adjacent geosynthetic sheets, $n=2$; unit weight of soil, $\gamma_{s}=19.0 \mathrm{kN} / \mathrm{m}^{3}$; soil friction angle, $\varphi=40^{\circ}$; equivalent depth of facing block, $B=$ $0.2 \mathrm{~m}$ (the equivalent depth of a facing block is the total horizontal surface area of the facing block divided by the nominal width of the block; equivalent depth is smaller than physical depth for a block containing hollow cores on its top and bottom surfaces); bulk unit weight of facing block, $\gamma_{b}=19.0 \mathrm{kN} / \mathrm{m}^{3}$ (the bulk unit weight of a facing block is the total weight of the block divided by the outer volume of the block; bulk unit weight is smaller than mass unit weight of the block material, i.e., concrete, for a block containing hollow cores); block-block friction angle, $\delta_{b b}=35^{\circ}$; geosynthetic-block friction angle $\delta_{g b}=30^{\circ}$; soil-block friction angle $\delta_{s b}=(2 / 3) \varphi=27^{\circ}$; and surcharge, $q=$ $10 \mathrm{kPa}$ (the typical design traffic surcharge).

The driving forces and resisting forces at (a) geosynthetic-block interface and (b) block-block interface for the baseline case are shown in Fig. 5. It is seen that the resisting forces are greater than driving forces at all depths for both block-block interface and geosynthetic-block interface of the baseline case. All the forces, as well as the difference between resisting forces and driving forces, are seen to increase with depth. The difference between the resisting and driving forces is somewhat smaller at the geosynthetic-block interface than that at the block-block interface for the baseline case.

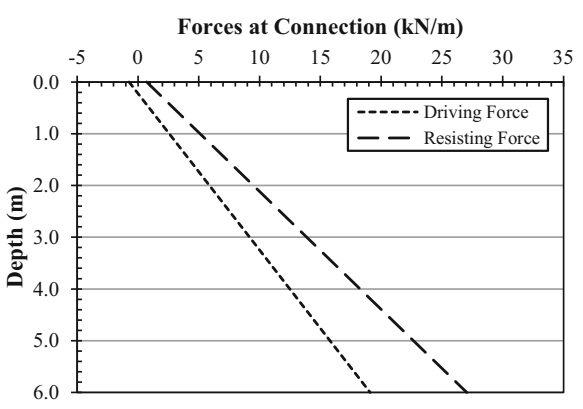

(a)

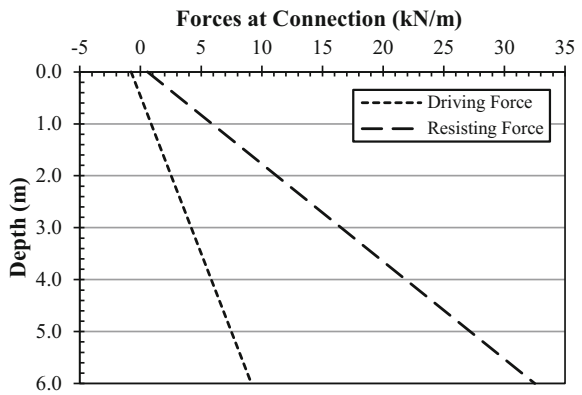

(b)

Fig. 5 Driving and resisting connection forces for the baseline case, at a geosynthetic-block interface and $\mathbf{b}$ block-block interface 
The effects of the following parameters were then examined: (a) number of facing blocks between adjacent geosynthetic sheets, $n$; (b) block-block friction angle, $\delta_{\mathrm{bb}}$; (c) geosynthetic-block friction angle $\delta_{\mathrm{gb}}$; (d) bulk unit weight of facing block, $\gamma_{\mathrm{b}}$; (e) equivalent depth of facing block, $B$; and (f) soil friction angle, $\varphi$, with which the soilblock friction angle $\delta_{\mathrm{sb}}$ was taken as two third of soil friction angle, i.e., $\delta_{s b}=(2 / 3) \varphi$. Each parameter was examined by varying the value of the parameter while keeping the values of all other parameters the same as those in the baseline case. Table 1 shows all the parameters and the values of the parameters that were examined in the parametric study.

Figure 6 shows the net connection forces versus depth relationships under $10-\mathrm{kPa}$ surcharge (typical design traffic load) for 1, 2, and 3 blocks between successive reinforcement layers, i.e., $n=1, n=2$, and $n=3$. Net connection force is defined herein as resisting force minus driving force. If the net connection force is positive, there will be no connection failure at that depth; otherwise, connection failure is said to occur. Of note, for $n=2$ and $n=3$, the net connection forces at both geosynthetic-block interface and block-block interface were examined. For all the cases shown in Fig. 6, the net connection forces are seen to be greater than 0 , except for the lower one third of the wall in the case of $n=3$. For both $n=2$ and $n=3$, with $\delta_{b b}=35^{\circ}$ and $\delta_{g b}=30^{\circ}$, the net connection forces are significantly smaller at the geosynthetic-block interfaces than at the block-block interfaces, which indicates that the margin of safety at the connection is higher at the block-block interface. When comparing the most critical interface condition (i.e., net connection forces at geosynthetic-block interface), the net connection force is the largest for $n=1$ (i.e., reinforcement spacing of $0.2 \mathrm{~m}$ ) and smallest for $n=3$ (i.e., reinforcement spacing of $0.6 \mathrm{~m}$ ). In other words, in terms of facing connection stability, it is favorable to keep reinforcement spacing as small as possible. The close reinforcement spacing (spacing $\leq 0.3 \mathrm{~m}$ ), as stipulated by FHWA GRS-IBS [2, 3], is found to be beneficial to both components of a reinforced soil wall, i.e., significantly increased stiffness and strength of the reinforced soil mass (as noted earlier in Introduction) and improved safety margin of the segmental facing.

Table 1 Parameters and their values examined in the study

\begin{tabular}{ll}
\hline Parameter & Values $^{\mathrm{a}}$ \\
\hline Wall height, $H$ & $(6 \mathrm{~m})$ \\
Height of facing block, $h$ & $(0.2 \mathrm{~m})$ \\
Number of facing blocks between adjacent geosynthetic sheets, $n$ & $(1), 2,3$ \\
Unit weight of soil, $\gamma_{\mathrm{s}}$ & $\left(19.0 \mathrm{kN} / \mathrm{m}^{3}\right)$ \\
Bulk unit weight of facing block, $\gamma_{\mathrm{b}}$ & $\left(19.0 \mathrm{kN} / \mathrm{m}^{3}\right), 29 \mathrm{kN} / \mathrm{m}^{3}, 39 \mathrm{kN} / \mathrm{m}^{3}$ \\
Equivalent depth of facing block, $B$ & $(0.2 \mathrm{~m}), 0.3 \mathrm{~m}, 0.4 \mathrm{~m}$ \\
Soil friction angle, $\varphi$ & $34^{\circ}, 37^{\circ},\left(40^{\circ}\right)$ \\
Soil-block friction angle, $\delta_{\mathrm{sb}}=(2 / 3) \varphi$ & $23^{\circ}, 25^{\circ},\left(27^{\circ}\right)$ \\
Block-block friction angle, $\delta_{\mathrm{bb}}$ & $30^{\circ},\left(35^{\circ}\right), 40^{\circ}$ \\
Geosynthetic-block friction angle $\delta_{\mathrm{gb}}$ & $25^{\circ},\left(30^{\circ}\right), 35^{\circ}$
\end{tabular}

${ }^{\mathrm{a}}$ Values in parentheses are for the baseline case 
Net Forces at Connections $(\mathrm{kN} / \mathrm{m})$

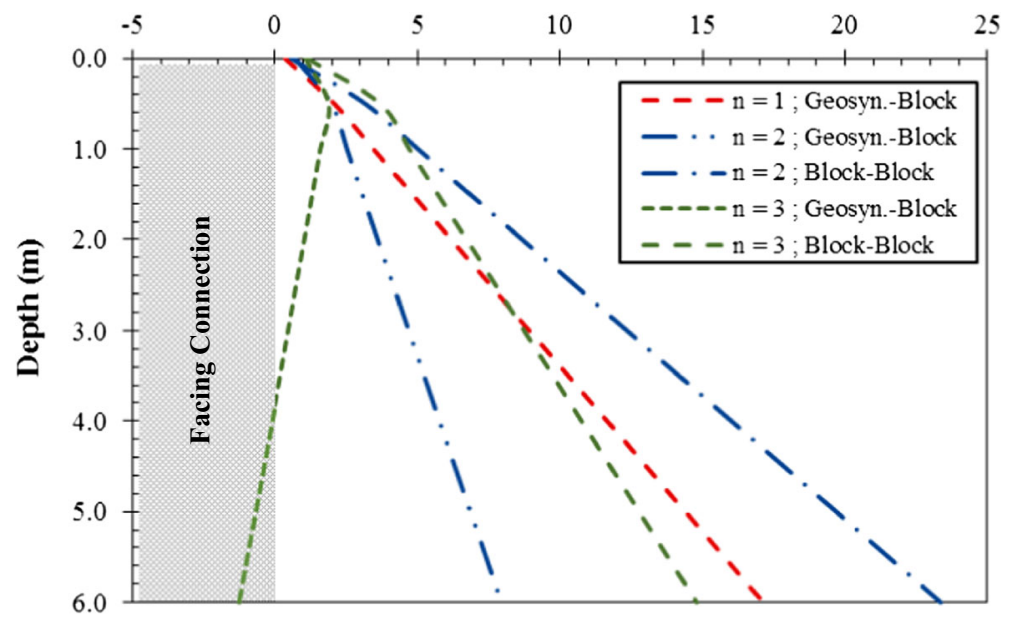

Fig. 6 Net connection forces at geosynthetic-block interface and block-block interface with 1, 2, and 3 blocks between successive reinforcement layers, under 10-kPa surcharge

The effect of block-block interface friction angle $\left(\delta_{\mathrm{bb}}\right)$ on net connection forces for $n=2$ and $n=3$ are shown in Fig. 7. Three different values of $\delta_{\mathrm{bb}}$ were examined: $30^{\circ}$, $35^{\circ}$, and $40^{\circ}$, with $\delta_{\mathrm{gb}}$ being equal to a constant value of $30^{\circ}$. As to be expected, the net connection forces are seen to increase with increasing value of $\delta_{\mathrm{bb}}$. The net connection forces are somewhat larger for $n=2$ than $n=3$, and both are greater than 0 at all depths. Note that there is a slight change in slope on the net connection forces versus depth relationship that occurs between 0 and $1.0 \mathrm{~m}$ from the top of the wall, which is more noticeable for $n=3$ than for $n=2$. This is a result of the driving force within these depths being of negative values. Since geosynthetic reinforcement cannot resist any compressive loads, the driving forces within those depths were set equal to 0 , hence the change in slopes.

The effect of geosynthetic-block interface friction angle $\left(\delta_{\mathrm{gb}}\right)$ on net connection forces for $n=2$ and $n=3$ is shown in Fig. 8. Three different values of $\delta_{\mathrm{gb}}$ were examined: $25^{\circ}, 30^{\circ}$, and $35^{\circ}$, with a constant value of $\delta_{b b}=35^{\circ}$. Similar to the effect of $\delta_{\mathrm{bb}}$ (Fig. 7), the net connection forces are also seen to be larger for $n=2$ than those for $n=3$. There is a change in slope on the net connection forces versus depth

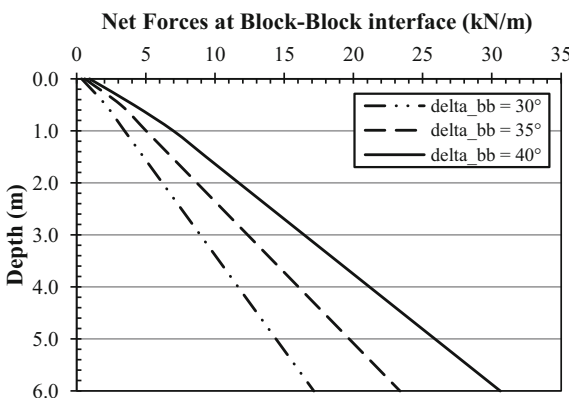

(a)

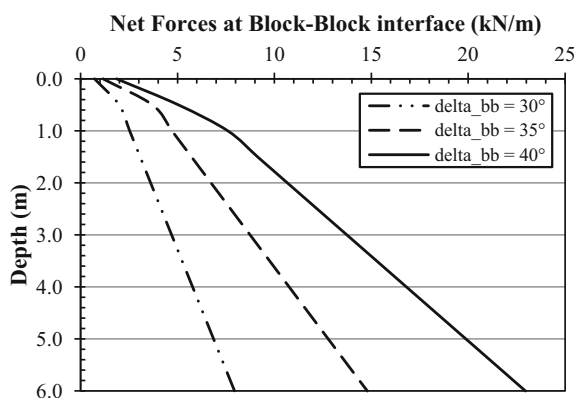

(b)

Fig. 7 Net block-block connection forces versus depth, for a $n=2$ and $\mathbf{b} n=3$ 
relationship between 0 and about $0.5 \mathrm{~m}$ from the top of the walls, which is rather distinct for $n=3$. For $n=3$ and $\delta_{g b}=25^{\circ}$ or $30^{\circ}$, the net connection forces are seen to decrease with depth; for $\delta_{g b}=25^{\circ}$, nearly the entire wall has negative net connection forces; for $\delta_{g b}=30^{\circ}$, negative net connection forces are seen in the bottom third of the wall, which also means if the height of the wall had been $4 \mathrm{~m}$ or lower, connection failure will not occur. The decrease of net connection force with depth is a result of the rate of increase in the driving force with depth being greater than the rate of increase in the resisting force. For $\delta_{g b}=35^{\circ}$ and $n=3$, however, the net connection forces are positive and increase with depth. Figure 8 suggests that (a) net connection force appears to be rather sensitive to $\delta_{\mathrm{gb}}$ value; unless the geosynthetic-block interface friction is sufficiently high $\left(35^{\circ}\right.$ or higher in this case), facing connection failure may occur, and (b) the safety margin for geosynthetic-block connection failure is much higher for $n=2$ than that for $n=3$.

The effects of the bulk unit weight of facing block, $\gamma_{\mathrm{b}}$, and equivalent depth of facing block, $B$, are shown in Fig. 9a, b, respectively. The former was examined by varying the bulk unit weight of facing block $\left(\gamma_{\mathrm{b}}\right)$ as 19,29 , and $39 \mathrm{kN} / \mathrm{m}^{3}$ and the latter by varying the equivalent depth of facing block $(B)$ as $0.2,0.3$, and $0.4 \mathrm{~m}$. The net connection forces at geosynthetic-block interface and block-block interface are seen to be positive and increase with depth. As to be expected, the net connection forces are seen to increase with bulk unit weight and equivalent depth of the facing block.

Figure 10 shows the relationships between net connection forces and depth for soil friction angle $(\varphi)$ of $34^{\circ}, 37^{\circ}, 40^{\circ}$, with the corresponding soil-block interface friction angle being $\delta_{s b}=(2 / 3) \varphi$. For $\varphi=34^{\circ}$, which is generally considered the lower bound of permissible friction angle as the backfill for reinforced soil walls, the net connection forces at geosynthetic-block interface are rather small (on the order of $1.0 \mathrm{kN} / \mathrm{m}$ ) and are nearly uniform. For $\varphi=40^{\circ}$, the net connection forces are very much higher. The benefit of good compaction for connection, as reflected by a higher friction angle, is obvious.

\section{Summary and Concluding Remarks}

Based on force equilibrium, equations of driving forces and resisting forces at facing connections of segmental reinforced soil walls are derived for situations where

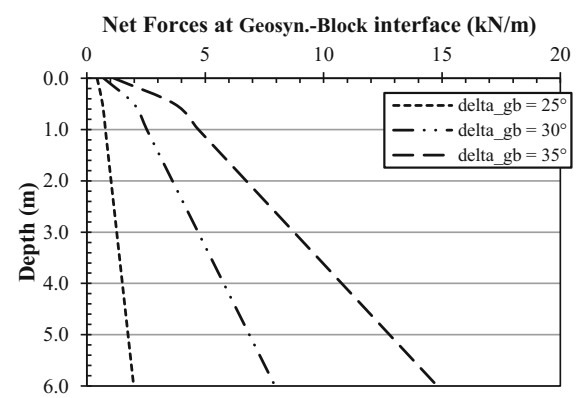

(a)

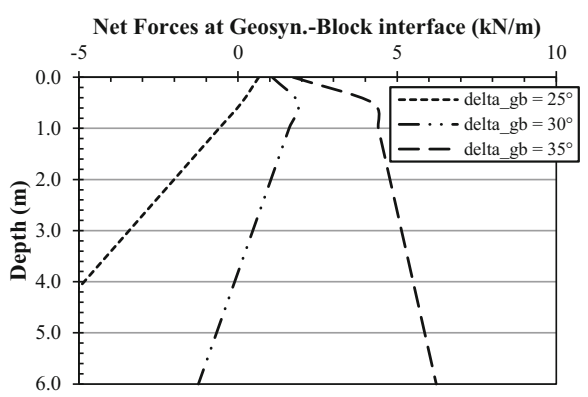

(b)

Fig. 8 Net geosynthetic-block connection forces versus depth, for $\mathbf{a} n=2$ and $\mathbf{b} n=3$ 


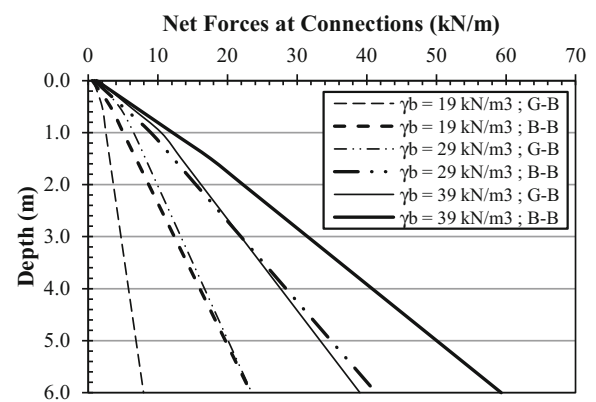

(a)

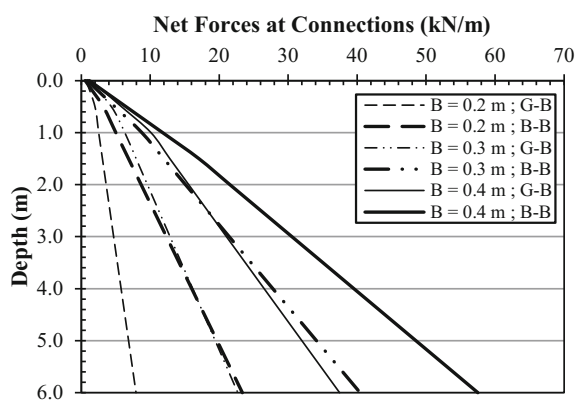

(b)

Fig. 9 Net connection forces versus depth, as affected by a bulk unit weight of facing block and b equivalent depth of facing block, $B$

reinforcement is at every course of facing blocks and at every three courses of facing blocks. From these equations, generalized equations of driving and resisting forces for any number courses of blocks between adjacent reinforcement layers (i.e., Eqs. (24) to (27)) are developed. For the driving forces, the lateral earth pressure exerted on segmental facing is assumed to be the Rankine active earth pressure. The assumption of Rankine active earth pressure can be very conservative, especially when lightweight facing blocks are employed. A recent study conducted by the FHWA has concluded that the bin pressure postulate, as described in the Introduction, would prevail, i.e., the lateral earth pressure is very small for small reinforcement spacing and does not increase with depth [9]. Also of note is that there is likely significant stress redistribution in the soil behind facing blocks, before a limit state of facing failure is reached. The Rankine earth pressure is assumed in this study because it is used in most design methods for reinforced soil walls with extensible reinforcement, such as geosynthetics. For the resisting forces, it is assumed that there are no connection enhancement elements (such as pins, lips, or keys) between vertically adjacent facing blocks. The connection resistance is derived entirely from friction between contacting blocks.

Using the generalized connection force equations, the driving and resisting forces for some common parameter values, under typical wall conditions with lightweight

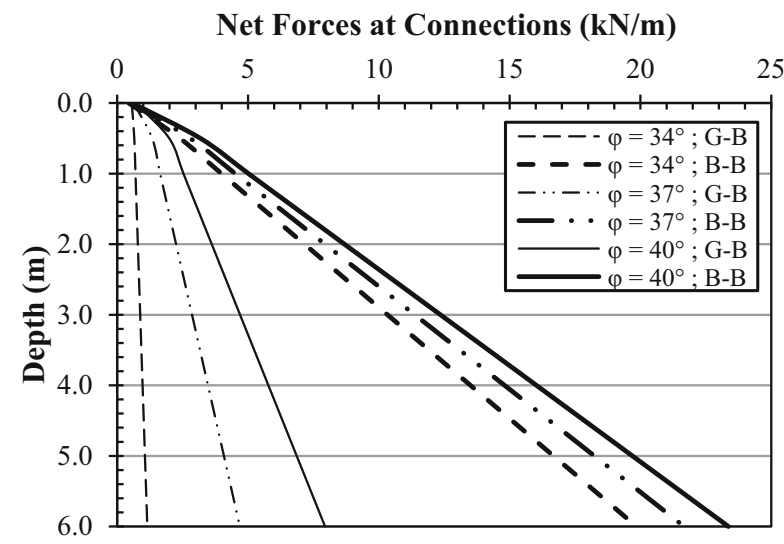

Fig. 10 Net connection forces at geosynthetic-block interface and block-block interface versus depth, as affected by friction angle of soil 
concrete blocks, and subject to $10-\mathrm{kPa}$ surcharge (typical design traffic load) were determined. The calculated connection forces indicate the following:

- Subject to typical traffic loads, the net connection forces (net connection force= resisting force-driving force; positive net connection force indicates stable connection) are all positive for segmental reinforced soil walls with lightweight blocks without connection enhancement elements and reinforcement spacing of 0.2 and $0.4 \mathrm{~m}$. In all the cases examined, the net connection forces in the top $0.5 \mathrm{~m}$ are small; the common practice of using adhesives to increase connection strength of the top two to three courses of lightweight facing blocks is a sound measure.

- For segmental reinforced soil walls with 0.6-m reinforcement spacing, the net connection force is rather sensitive to the frictional angle at geosynthetic-block interface; unless the geosynthetic-block interface friction is sufficiently high $\left(35^{\circ}\right.$ or higher in this case), facing connection failure is likely to occur.

- Close reinforcement spacing in GRS (defined by the FHWA as walls with reinforcement spacing $\leq 0.3 \mathrm{~m}$ ), which has been shown to significantly improve stiffness and strength of a reinforced soil mass, is also quite beneficial for improving facing stability of segmental reinforced soil walls.

- For segmental reinforced soil walls of lightweight facing blocks and friction-only connection and with reinforcement spacing of 0.2 and $0.4 \mathrm{~m}$, the net connection forces increase with depth. Under typical traffic loads, there is no limit to wall height in terms of connection failure for segmental GRS walls. The satisfactory performance of the 16.7-m-high wall as shown in Fig. 2 is of no surprise. Note that this is not true for reinforcement spacing of $0.6 \mathrm{~m}$. The common perception that a higher wall is more susceptible to connection failure (e.g., [7]) applies only to segmental walls with larger reinforcement spacing.

- As can be expected, the stability of facing connections can be improved appreciably by increasing the bulk unit weight of facing blocks, equivalent depth of facing blocks, and/or friction angle of the backfill (e.g., with greater compaction effort).

On a related note, many builders of segmental geosynthetic walls have opted for the use of pins, blocks with lips or keys, and/or heavyweight blocks to improve facing stability. These measures tend to attract more loads to the connection and increase the earth thrust exerted behind the wall face (i.e., much larger than the Rankine thrust). As a result, the resisting and driving forces at the facing connections are both increased. They may not necessarily improve facing stability.

\section{References}

1. American Association of State Highway and Transportation Officials (AASHTO): LRFD Bridge Design Specifications, Edition 5. (2010)

2. Adams, M.T., Nicks, J., Stabile, T., Wu, J.T.H., Schlatter, W., Hartmann, J.: Geosynthetic reinforced soil integrated bridge system interim implementation guide. Report No. FHWA-HRT-11-026, Federal Highway Administration, McLean, VA (2011a)

3. Adams, M.T., Nicks, J., Stabile, T., Wu, J.T.H., Schlatter, W., Hartmann, J.: Geosynthetic reinforced soil integrated bridge system synthesis report. Report No. FHWA-HRT-11-027, Federal Highway Administration, McLean, VA (2011b) 
4. Barrett, R.K.: Retaining-wall dialog: a tale of two walls. Geosynthet. August 2006 Issue (2006)

5. Barrett, R.K., Ruckman, A., Wu, J.T.H., Adams, M.: Reinforced soil: a new paradigm for building bridges. Keynote Lecture.pp. 1-25. New Development in Reinforced Soil Retaining Structures, Taiwan (2000)

6. Berg, R.R. Christopher, B.R., Samtani, N.C.: Design of mechanically stabilized Earth walls and reinforced soil slopes, design \& construction guidelines. Report No. FHWA-NHI-00-043. Federal Highway Administration, March. 394 pp. (2009)

7. Dallaire, G.: Segmental retaining walls come of age. Erosion control. J. Int. Erosion Contr. Assoc. November-December, 2001 Issue (2001)

8. Elton, D.J., Patawaran, M.A.B..: Mechanically stabilized earth reinforcement tensile strength from tests of geotextile-reinforced soil. J. Trans. Res. Board No. 1868, TRB, National Research Council, Washington, D.C., 81-88. (2004)

9. Iwamoto, M.K., Ooi, P.S.K., Adams, M.T., Nicks, J.E.: Composite properties from instrumented load tests on soil columns reinforced with geotextiles. Transportation Board 93rd Annual Meeting, Washington, D.C. (2014)

10. Iwamoto, M.K., Ooi, P.S.K., Nicks, J.E., Adams, M.T.: Use of fully softened versus peak strength to predict the capacity of footings on geosynthetic reinforced soil. Third International Conference on Geotechnique, Construction Materials and Environment, Nagoya, Japan, pp. 252-257. (2013)

11. Leshchinsky, D., Ling, H.I., Hanks, G.: Unified design approach to geosynthetic reinforced slopes and segmental walls. Geosynthet. Int. 2(5), 845-881 (1995)

12. Nicks, J.E., Adams, M.T., Ooi, P.S.K.: Geosynthetic reinforced soil 1 performance testing-axial load deformation relationships. Federal Highway Administration, Report No. FHWA-HRT-13-066, McLean, VA. (2013)

13. Tatsuoka, F.: Roles of facing rigidity in soil reinforcing, earth reinforcement practice, keynote lecture. In: Ochiai, H., Hayashi, S., Otani, J. (eds.) Balkema, 1993, Proceedings of the International Symposium on Earth Reinforcement Practice, IS Kyushu ‘92, Vol. 2, Kyushu, Fukuoka, Japan, November 1992, pp. 831870. (1993)

14. Wu, J.T.H.: Revising the AASHTO Guidelines for Design and Construction of GRS Walls. Colorado Department of Transportation, Report No. CDOT-DTD-R-2001-16. 148 pp. (2001)

15. Wu, J.T.H.: Lateral Earth Pressure against the Facing of Segmental GRS Walls. Geosynthetics in reinforcement and hydraulic application, Geo-Denver 2007: New Peaks in Geotechnics. American Society of Civil Engineers. (2007)

16. Wu, J.T.H., Adams, M., Pham, Q., Lee, S.H., Ma, C.: A generic soil-geosynthetic composite test. Int. J. Geotech. Eng. 6(1), 103-116 (2012)

17. Wu, J.T.H., Pham, T.Q.: Load carrying capacity and required reinforcement strength of closely spaced soil-geosynthetic composites. J. Geotech. Geoenviron. Eng. ASCE 139(9), 1468-1476 (2013) 